\title{
Beware of tainted slimming and anti-obesity products
}

\section{Opinion}

Yes, we all know we've gained some pounds from too much food (and for some people, stress) over the holidays, so we're anxious to take it all off as fast as possible as life returns to normal.

This is where some people are tempted to cut corners. Instead of having a healthy diet and exercise, they allow themselves to be lured by shady marketers promising 'instant', 'all-natural' and 'effective' weight loss products with the idea that simply taking their magic potion would make you fit back to your old high school clothes, no strings attached.

On the other side of the world, the Philippine Food and Drug Administration recently cautioned people to be wary of weight lossinducing products-and for good reason, as these "health" products marketed as oral capsules, coffee or tea drinks are tainted with harmful and regulated substances such as amphetamine, sibutramine, and steroids.

\section{What are these nasties and why should anyone using them be concerned?}

Amphetamine is an addictive substance that is dangerous when misused. It functions as an appetite suppressant in slimming products, but they affect many different parts of the body and result to side effects that are severe, even fatal. In 1979 the USFDA banned its use in diet pills due to a number of deaths being attributed to it.

In January 2010 a study found that the drug Sibutramine-used in weight loss products to suppress the appetite and stimulate metabolism-increased the risk of heart attacks and strokes in patients receiving the drug. This prompted the European Union to ban the use of Sibutramine for weight reduction purposes. Major pharmaceuticals in other countries such as South Africa followed suit and also withdrew their products containing this compound.

Fat burning steroids, meanwhile, are intended for increasing metabolism, gaining muscle mass and encouraging weight loss. However, using this is generally unsafe due to its various side effects that include heart problems, blood pressure fluctuations, headaches and dizziness, infertility and even changes in personality. In addition, whatever weight loss you thought you achieved will creep right back because the body cannot sustain such a rapid increase in metabolism without the steroid to act as stimulant.

You would think that such encouraging names as "Perfect Slim Purely Natural Fat Reduction Cosmetic", "Perfect Figure Slimming", "Pretty Model -Qiaomei Fat Binder" and "Seven Days Miracle -Shaping Body Fat Loss" would have you on the Victoria's Secret
Volume 5 Issue 3 - 2016

\author{
Susan Meyer \\ CIM President, Canada
}

Correspondence: Susan Meyer, CIM President, 2824I Crown Valley Parkway, Suite F-4I 5 Laguna Niguel, CA 92677, Canada, Tel I888708 SLIM (7546), Fax I8663733094,

Email smeyer@cortislim.com

Received:September 27, 2016 | Published: November 15, 2016

runway or a Cosmo photo shoot in no time. Well, they may be effective at shedding weight initially, but the prices you have to pay is too high-think of depression and suicidal thoughts, heart attacks, painful urination, convulsions, brain haemorrhage, comatose, death. In any of these states, does a coca-cola figure matter still? NOT worth it at all.

Last year, the USFDA found amphetamine-like substances in 9 "all-natural" weight loss products currently on the market. The agency also found another substance, Acacia rigidula, whose safety for human consumption has not been tested yet.

But it doesn't mean that we should entirely junk the idea of using weight loss products, no. Diet pills and weight loss supplements, when complemented with a healthy lifestyle and used with a qualified physician's guidance, aids in our slimming efforts, boosting it and ensuring that the shedding of pounds is sustained for the long term. Some products like CortiSLIM also address specific issues that contribute to weight gain-in our case, that of exposure to chronic stress.

Look for products that are not tainted with ingredients that are addictive have dangerous side effects or whose safety is medically unproven. To know which products you should avoid, view the list of US Food and Drug Administration's banned products:

http://www.fda.gov/Drugs/ResourcesForYou/Consumers/ QuestionsAnswers/ucm136187.htm

\section{Acknowledgements}

None.

\section{Conflict of interest}

The author declares no conflict of interest. 